\title{
Thrombocytopenia during pregnancy in women with HIV infection receiving no treatment
}

\author{
H M Sebitloane, MB ChB, FCOG (SA), MMed \\ Department of Obstetrics and Gynaecology, School of Clinical Medicine, College of Health Sciences, Nelson R Mandela \\ School of Medicine, University of KwaZulu-Natal, Durban, South Africa
}

Corresponding author: H M Sebitloane (sebitloanem@ukzn.ac.za)

\begin{abstract}
Background. Thrombocytopenia (TCP) complicates $5-8 \%$ of pregnancies. Most cases of TCP are gestational, and the condition is usually mild and occurs in the latter part of pregnancy. Apart from pregnancy-associated medical complications such as pre-eclampsia, HIV infection is a recognised cause of TCP, and a relatively high prevalence of TCP during pregnancy would be expected in a setting with a high antenatal seroprevalence of HIV.

Methods. This was a sub-analysis of the data from a prospective trial in which the incidence of postpartum sepsis in HIV-infected women was compared with that in HIV-uninfected women. Women who were considered at low risk and eligible for vaginal delivery were recruited at 36 weeks' gestation, and followed up for 6 weeks after delivery. Full blood counts and CD4 counts of HIV-infected women were obtained at baseline and repeated 6 weeks after delivery.

Results. The prevalence of TCP was 5.3\% during pregnancy and $1.2 \% 6$ weeks after delivery. The prevalence was similar among HIV infected $(6.0 \%)$ and HIV-uninfected women $(4.7 \%)(p=0.292)$. Among the HIV-infected women, who were not receiving antiretroviral therapy (mean CD4 cell count of 453 cells/ $\mu \mathrm{L}$ ), there was no significant association between immunosuppression and the severity of TCP. Conclusions. Most of the TCP seen during pregnancy is of the gestational variety, and in this study HIV infection did not increase its prevalence or its severity.
\end{abstract}

S Afr Med J 2016;106(2):210-213. DOI:10.7196/SAMJ.2016.v106i2.9903

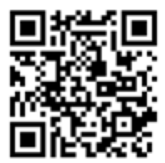

Thrombocytopenia (TCP) (platelet count $<150 \times$ $10^{9} / \mathrm{L}$ ) during pregnancy often causes anxiety among both patients and healthcare practitioners. It occurs in $5-8 \%$ of pregnancies, the prevalence depending on whether it is associated with medical disorders or not. ${ }^{[1,2]}$ Gestational TCP (gTCP), also known as incidental or benign TCP of pregnancy, accounts for approximately $80 \%$ of all cases of TCP occurring in pregnancy ${ }^{[1]}$ and typically develops in the late second or third trimester when physiological haemodilution leads to an increased mean platelet volume and subsequent accelerated consumption. Women with gTCP are usually asymptomatic, their low platelet count being detected as part of routine antenatal screening. Fetal TCP is usually mild and transient, requiring no intervention. ${ }^{[3]}$ A history of gTCP is sometimes obtained, as there is the potential for it to recur. A recurrence rate of $13.6 \%$ was noted in a series of 22 cases ${ }^{[4]}$ while among 37 patients with gTCP, Ruggeri et al. ${ }^{[3]}$ reported $100 \%$ recurrence in 4 women who had repeat pregnancies. ${ }^{[3]}$

gTCP is usually mild (platelet count $100-150 \times 10^{9} / \mathrm{L}$ ), and although the minimum threshold has never been established, counts of $\leq 70 \times 10^{9} / \mathrm{L}$ are uncommon. ${ }^{[5]}$ Severe TCP $\left(\leq 50 \times 10^{9} / \mathrm{L}\right)$ is rare, occurring in $\leq 0.1 \%$ of pregnancies. ${ }^{[6]}$ In these cases, pathological causes of increased destruction or utilisation of platelets such as preeclampsia/eclampsia, the HELLP syndrome (haemolysis, elevated liver enzymes and low platelet count), and microangiopathies such as thrombotic thrombocytopenic purpura, (auto)immune thrombocytopenic purpura, haemolytic uraemic syndrome and haemolysis are likely. Viral infections such as viral hepatitis and infection with cytomegalovirus and HIV may also cause TCP.

In the era of HIV, particularly in South Africa (SA), where the seroprevalence in the antenatal population exceeds $25 \%$, clinicians may not be able to differentiate gTCP from that associated with HIV. TCP has been reported to be present in $5-9 \%$ of patients who have
HIV infection but are asymptomatic, and in $21-40 \%$ of those with AIDS. ${ }^{[6,7]}$ Although TCP was initially thought to occur early in the course of HIV infection, reports have shown a correlation between TCP and low CD4 counts. ${ }^{[6,7]}$ Moreover, TCP has been shown to correlate with a poorer prognosis and rapid progression to AIDS. ${ }^{[7,8]}$ Transient TCP is a feature of the acute retroviral syndrome seen in primary HIV infection. ${ }^{[9]}$ The two mechanisms involved in HIVassociated TCP are thought to be immune-mediated destruction of platelets (in early infection) and a defect in platelet production (in advanced disease) ${ }^{[8]}$ HIV also directly infects megakaryocytes, causing apoptosis and dysmegakaryopoiesis ${ }^{[8]}$ Individuals with HIVassociated TCP have a clinical presentation and response to therapy similar to that of idiopathic (immune) thrombocytopenic purpura (ITP). ${ }^{[10]}$ Apart from the severity and the time of onset of TCP in pregnant women with ITP (being more severe and occurring in earlier gestation), there is as yet no diagnostic test to differentiate gTCP from ITP, as circulating antibodies may be found in both conditions. $^{[11]}$

There are limited data on the prevalence of gTCP in HIV-infected women. In a clinical setting where patients may arrive unbooked and in labour, or without a previous platelet count, it becomes important to establish the role of HIV in TCP.

\section{Methods}

This was a sub-analysis of data from a prospective longitudinal study aimed at determining the effect of HIV on postpartum infectious morbidity. The cohort comprised HIV-infected $(n=675)$ and HIV-uninfected $(n=648)$ women attending King Edward VIII Hospital, Durban, SA, between 2005 and 2007. Participants were recruited at $\geq 36$ weeks' gestation. They had to be at low risk with no obstetric morbidities, and eligible for a vaginal delivery. Ethical approval for the parent study was obtained from the University of 
KwaZulu-Natal BioMedical Research Ethics Committee (Ref. H031/01).

At baseline all women had full blood counts (FBCs), and CD4 counts if HIVinfected. They were reviewed on three occasions in the post-delivery period, and tests were repeated 6 weeks after delivery. TCP was defined as a platelet count of $\leq 150 \times 10^{9} / \mathrm{L}$. It was regarded as severe if the platelet count was $\leq 50 \times 10^{9} / \mathrm{L}$.

\section{Results}

Results were available for 1311 women (669 HIV-infected and $642 \mathrm{HIV}$-uninfected) at baseline, and for 897 (461 (68.9\%) of the HIV-infected and $436(67.9 \%)$ of the HIV-uninfected) women at 6 weeks. None of the HIV-infected participants received combination antiretroviral therapy (ART) as the standard of care at the time was only single-dose nevirapine. The HIVinfected and HIV-uninfected groups were comparable in terms of age, parity and body mass index (Table 1). The baseline FBC results are also shown in Table 1. HIVinfected women had significantly lower baseline haemoglobin $(\mathrm{Hb})$ concentrations and total white cell counts (WCCs) than $\mathrm{HIV}$-uninfected women. The mean $\mathrm{Hb}$ at baseline was $11.1 \mathrm{~g} / \mathrm{dL}$ for $\mathrm{HIV}$-infected women and $11.7 \mathrm{~g} / \mathrm{dL}$ for $\mathrm{HIV}$-uninfected women $(p<0.001)$. Twenty-three percent of the women had an $\mathrm{Hb}$ of $\leq 10.5 \mathrm{~g} / \mathrm{dL}$; these comprised $30.1 \%$ of the HIV-infected group compared with $16.4 \%$ of the HIV-uninfected group $(p<0.001)$. The mean CD4 count of the $\mathrm{HIV}$-infected women was 453 cells $/ \mu \mathrm{L}$ at enrolment, increasing by $22 \%$ to a mean of 552 cells $/ \mu \mathrm{L}$ at 6 weeks postpartum. Women with CD 4 counts of $<200$ cells $/ \mu \mathrm{L}$ ( $11.1 \%$ of the HIV-infected population) had a mean CD 4 count at enrolment of 129 cells/ $\mu \mathrm{L}$ and a mean count of 131 cells/ $\mu \mathrm{L} 6$ weeks after delivery.

The mean platelet count was $243.2 \times 10^{9} / \mathrm{L}$ in the HIV-infected group (range 84 - 533) and $247.4 \times 10^{9} / \mathrm{L}$ in the HIV-uninfected group (range 26 - 597) $(p=0.354)$ (Table 1). The incidence of gTCP was 40/669 (5.9\%) in the HIV-infected and 30/642 (4.7\%) in the HIV-uninfected women at baseline (relative risk (RR) 1.28; 95\% confidence interval (CI) $0.81-2.03 ; p=0.292$ ) (Table 2). The TCP was mild in both groups, with only $3 \mathrm{HIV}$-uninfected and $4 \mathrm{HIV}$-infected women in each group having platelet counts of $\leq 100 \times 10^{9} / \mathrm{L}$.

Among the HIV-infected women, TCP occurred at all ranges of CD4 counts and was not associated with immunosuppression (CD4 count $<200$ cells $/ \mu \mathrm{L}$ ). On the contrary, TCP occurred with increasing frequency

Table 1. Demographic data (means)

\begin{tabular}{llll}
\hline & $\begin{array}{l}\text { HIV-infected } \\
(\mathbf{N}=\mathbf{6 6 9})\end{array}$ & $\begin{array}{l}\text { HIV-uninfected } \\
(\boldsymbol{N}=\mathbf{6 4 2})\end{array}$ & $\boldsymbol{p}$-value \\
\hline Age (years) & 26.7 & 26 & 0.048 \\
Weight $(\mathrm{kg})$ & 80.7 & 79.8 & 0.774 \\
Parity & 1.0 & 1.0 & 0.667 \\
Height $(\mathrm{m})$ & 1.7 & 1.8 & 0.272 \\
Gestational age $($ wks $)$ & 36.8 & 37 & 0.051 \\
Hb $(\mathrm{g} / \mathrm{dL})$ & 11.1 & 11.7 & $<0.001$ \\
WCC $\left(\times 10^{9} / \mathrm{L}\right)$ & 7.8 & 8.7 & $<0.001$ \\
Lymphocytes $\left(\times 10^{9} / \mathrm{L}\right)$ & 2.1 & 2.2 & 0.907 \\
Platelets $\left(\times 10^{9} / \mathrm{L}\right)$ & 243.2 & 247.4 & 0.354
\end{tabular}

Table 2. Thrombocytopenia at baseline

\begin{tabular}{|c|c|c|c|c|c|}
\hline \multirow[b]{2}{*}{ Platelets $\left(\times 10^{9} / \mathrm{L}\right)$} & \multicolumn{4}{|c|}{$\begin{array}{l}\text { HIV-positive according to CD4 count } \\
\text { (cells/ } / \mathrm{L})(N=669)\end{array}$} & \multirow{2}{*}{$\begin{array}{l}\text { HIV-negative } \\
(N=642)\end{array}$} \\
\hline & $<\mathbf{2 0 0}$ & $200-350$ & $351-500$ & $>500$ & \\
\hline$<100, n$ & 0 & 0 & 3 & 1 & 3 \\
\hline $100-150, n$ & 6 & 10 & 8 & 12 & 27 \\
\hline$\%^{*}$ & 15.0 & 25.0 & 27.5 & 32.5 & \\
\hline Total, $n(\%)$ & \multicolumn{4}{|c|}{$40(6.0)^{\dagger}$} & $30(4.7)^{\dagger}$ \\
\hline
\end{tabular}

with increasing CD4 counts (Table 2). The non-parametric test showed a low correlation of 0.062 . Three participants (all HIVinfected) were found to have puerperal sepsis (endometritis), their infection resolving on first-line antibiotics.

For 461 HIV-infected women and 436 HIV-uninfected women, both the baseline and 6 weeks post-delivery platelet measurements were available. Eleven women had TCP at the 6-week assessment (6 HIVinfected women (1.3\%) and $5 \mathrm{HIV}$-uninfected women $(1.2 \%))(p=0.881)$ (Table 3$)$. TCP had persisted from the antenatal period in 3 women in each HIV group (total 6); the remainder $(3 \mathrm{HIV}$-infected and $2 \mathrm{HIV}$ uninfected women) were new cases of TCP. The correlation between platelet counts and CD4 counts at baseline and 6 weeks for the 11 women with TCP in the postpartum period is shown in Table 4 . Of the 3 HIVinfected women with persistent TCP after the first assessment, only 1 (patient 3) was immunosuppressed according to the CD4 count. Of the 3 who had developed TCP for the first time in the postnatal period, only 1 (patient 4) was immunosuppressed.

\section{Discussion}

gTCP develops in up to $5 \%$ of all pregnancies in the third trimester. ${ }^{[1]}$ In the present study the overall prevalence of TCP during pregnancy was $5.3 \%$, and there was no statistical difference in the prevalence between women with and without HIV infection. Mandelbrot et al. ${ }^{[11]}$ found a comparable prevalence of TCP among HIVinfected pregnant women of $3.2 \%$; however, these authors associated $>80 \%$ of cases of TCP with HIV-positive status despite the study having no HIV-uninfected controls. In the present study, the prevalence of severe TCP $\left(<50 \times 10^{9} / \mathrm{L}\right)$ was very low despite half of the patients being HIVinfected. In a study of patients of unknown HIV status, with a sample size comparable to the present study, Dwivedi et al. ${ }^{[12]}$ reported an overall prevalence of TCP of $8 \%, 4 \%$ of cases being severe, and attributed this to the high prevalence of anaemia in their patients. ${ }^{[12]}$

There are several reasons why the TCP in the women in the present study was probably gestational: $(i)$ the prevalence rates are comparable to those reported in other series; ${ }^{[1,2]}$ (ii) in most of the women with TCP who had two readings (22/26 HIV-infected women and 18/21 HIV-uninfected women), the platelet counts returned to normal in the postpartum period; and (iii) most of the women had mild TCP, in keeping with previous reports on gTCP. ${ }^{[1,2]}$ Of the women 
with TCP at 6 weeks, low platelet counts had been detected in the antenatal period in 3 in each HIV group, and their TCP was mild $\left(>100 \times 10^{9} / \mathrm{L}\right)$, a feature not in keeping with ITP. One woman (patient 7 in Table 4) who had antenatal and post-delivery platelet counts of $81 \times 10^{9} / \mathrm{L}$ and $92 \times 10^{9} / \mathrm{L}$, respectively, may in fact have had ITP, although it has been reported that it may take as long as 12 weeks after delivery for platelet counts to recover ${ }^{[13]}$ and followup in the present study did not extend beyond 6 weeks. ITP could also have been responsible for the new development of TCP in 2 HIV-uninfected participants, as no other explanation could be found. Classic ITP occurs in the second or third decade of life, ${ }^{[3]}$ and complicates $1 / 1000-10000$ pregnancies. ${ }^{[12]}$ In a report of 117 patients with TCP at term, Subbiah et al. ${ }^{[14]}$ found $41 \%$ of cases to be gestational and $26 \%$ to be due to ITP. However, this was a selected high-risk group and does not represent the general obstetric population.

The development of new-onset TCP in 3 HIV-infected women could have been related to their HIV status. In the first case (patient 4 in Table 4), TCP was probably due to defective production of platelets. This woman was severely immunocompromised and had a low $\mathrm{Hb}$ and total WCC both at baseline and 6 weeks after delivery. She was not receiving any ART, in the context of Dominguez et al.'s ${ }^{[10]}$ finding that untreated HIV-infected thrombocytopenic individuals had lower platelet turnover than those treated with zidovudine. The TCP in the other 2 women was probably immune-

Table 3. Baseline and 6-week platelet counts according to HIV status

\begin{tabular}{llll}
\hline $\begin{array}{l}\text { Baseline platelets } \\
(\times \mathbf{1 0} / \mathbf{L})\end{array}$ & \multicolumn{2}{l}{$\mathbf{6}$-week platelets $(\times \mathbf{1 0} / \mathbf{L})$} & Total \\
\cline { 2 - 3 } $\begin{array}{l}\text { HIV-infected, } n(\%) \\
\quad<150\end{array}$ & $3(11.5)$ & $23(88.5)$ & 26 \\
$\quad>150$ & $3(0.7)$ & $432(99.3)$ & 435 \\
HIV-uninfected, $n(\%)$ & & & \\
$\quad<150$ & $3(15.0)$ & $18(85.7)$ & 21 \\
$>150$ & $2(7.2)$ & $413(92.8)$ & 415
\end{tabular}

mediated HIV-associated TCP, since both had relatively high CD4 counts. Immunologically competent HIV-infected individuals (as opposed to those who are immunosuppressed) would be expected to produce more antiplatelet antibodies, leading to increased platelet destruction; among $41 \mathrm{HIV}$-infected individuals with TCP, platelet destruction was more prominent in patients with high CD4 counts. ${ }^{[10]}$ It could be argued that the TCP in the HIV-infected participants (patients $1-3$ in Table 4) that was detected both in the antenatal period and at 6 weeks was also immunologically induced. If that is so, the prevalence of HIVrelated TCP during pregnancy in the present study would be $0.9 \%$, and while low platelet counts occurred mainly among women with CD counts of $>200$ cells $/ \mu \mathrm{L}$, the TCP was mild. While other studies have reported a relationship between the severity of the HIV infection and the occurrence or severity of TCP, ${ }^{[7]}$ this was not confirmed in the present study. Ambler et al. ${ }^{[15]}$ documented similar findings in a population of highly active antiretroviral therapy (HAART) recipients.

As this was a retrospective analysis, maternal TCP could not be correlated with neonatal platelet counts. However, the findings are relevant to inform clinical practice, serving as a baseline. In the current era of universal HAART for all pregnant HIV-infected women, it can be expected that HIV-related TCP will be less frequent. While it is recommended that all efforts be made to acquire a baseline $\mathrm{Hb}$ and platelet count for all patients who are about to give birth, a fresh sample is not always indicated, as some clinicians have insisted for fear of HIV-related TCP. This causes delay in management and may potentially lead to poor perinatal outcomes.

\section{Conclusion}

This analysis establishes that TCP in HIV-infected pregnant women is mainly a result of the pregnancy itself, and that HIV-related TCP is rare, even in women not receiving ART. This is reassuring for practitioners managing women who present 'unbooked' in labour and perhaps require emergency caesarean section, but for whom a previous platelet count is unavailable. A baseline FBC, including $\mathrm{Hb}$ and platelets, should ideally be obtained as part of antenatal care during the course of pregnancy, but needs to be repeated during labour only in women with pre-eclampsia or obstetric haemorrhage.

Table 4. Details of women with thrombocytopenia at 6 weeks

\begin{tabular}{|c|c|c|c|c|c|c|}
\hline & Patient No. & $\begin{array}{l}\text { Platelets at baseline, } \\
\times 10^{9} / \mathrm{L}\end{array}$ & $\begin{array}{l}\text { CD4 at baseline, } \\
\text { cells } / \mu \mathrm{L}\end{array}$ & $\begin{array}{l}\text { Platelets at } 6 \text { weeks, } \\
\times 10^{9} / \mathrm{L}\end{array}$ & $\begin{array}{l}\text { CD4 at } 6 \text { weeks, } \\
\text { cells } / \mu \mathrm{L}\end{array}$ & Probable cause \\
\hline \multicolumn{7}{|l|}{ HIV-infected } \\
\hline \multirow{3}{*}{$\begin{array}{l}\text { TCP at both } \\
\text { assessments }\end{array}$} & 1 & 101 & 235 & 114 & 253 & ?gTCP, ?HIV-TCP \\
\hline & 2 & 110 & 383 & 101 & 261 & ?gTCP, ?HIV-TCP \\
\hline & 3 & 133 & 116 & 113 & 170 & ?gTCP, ?HIV-TCP \\
\hline \multirow{3}{*}{$\begin{array}{l}\text { TCP only at } 6 \\
\text { weeks }\end{array}$} & 4 & 158 & 58 & 49 & 68 & HIV-TCP \\
\hline & 5 & 205 & 703 & 124 & 792 & HIV-TCP \\
\hline & 6 & 164 & 314 & 148 & 510 & HIV-TCP \\
\hline \multicolumn{7}{|l|}{ HIV-uninfected } \\
\hline \multirow{3}{*}{$\begin{array}{l}\text { TCP at both } \\
\text { assessments }\end{array}$} & 7 & 81 & & 92 & & ITP \\
\hline & 8 & 126 & & 109 & & ?gTCP \\
\hline & 9 & 82 & & 119 & & ?gTCP \\
\hline \multirow{2}{*}{$\begin{array}{l}\text { TCP only at } 6 \\
\text { weeks }\end{array}$} & 10 & 278 & & 94 & & ?ITP \\
\hline & 11 & 197 & & 129 & & ?ITP \\
\hline
\end{tabular}




\section{References}

1. Levy AJ, Murphy LD. Thrombocytopenia in pregnancy. J Am Board Fam Pract 2002;15(4):290-297. 2. Sullivan CA, Martin JN Jr. Management of the obstetric patient with thrombocytopenia. Clin Obste Gynecol 1995;38(3):521-534. [http://dx.doi.org/10.1097/00003081-199509000-00011]

3. Ruggeri M, Schiavotto C, Castaman G, et al. Gestational thrombocytopenia: A prospective study. Haematologica 1997;82(3):341-342.

4. Karim R, Sacher RA. Thrombocytopenia in pregnancy. Curr Hematol Rep 2004;3(2):128-133.

5. Anteby E, Shalev O. Clinical relevance of gestational thrombocytopenia of $<100,000 /$ microliters. Am Hematol 1994;47(2):118-122. [http://dx.doi.org/10.1002/ajh.2830470210]

6. Sloand EM, Klein HG, Banks SM, et al. Epidemiology of thrombocytopenia in HIV infection. Eur 6. Sloand EM, Klein HG, Banks SM, et al. Epidemiology of thrombocytopenia in HIV
Haematol 1992;48(3):168-172. [http://dx.doi.org/10.1111/j.1600-0609.1992.tb00591.x]

7. Volberding PA, Baker KR, Levine AM. Human immunodeficiency virus hematology. ASH Education Book 2003;2003(1):294-313. [http://dx.doi.org/10.1182/asheducation-2003.1.294]

Book 2003;2003(1):294-313. [http://dx.doi.org/10.1182/asheducatio

9. Lescale KB, Eddleman KA, Cines DB, et al. Antiplatelet antibody testing in thrombocytopenic pregnant women. Am J Obstet Gynecol 1996;74(3):1014-1018. [http://dx.doi.org/10.1016/S0002 9378(96)70342-3]
10. Dominguez A, Gamallo G, Gaercia R, et al. Pathophysiology of HIV related thrombocytopenia: An analysis of 41 patients. J Clin Pathol 1994;47(11):999-1003. [http://dx.doi.org/10.1136/jcp.47.11.999] 11. Mandelbrot L, Schlienger I, Bocigain A, et al. Thrombocytopenia in pregnant women infected with human immunodeficiency virus: Maternal and neonatal outcomes. Am J Obstet Gynecol 1994;171(1):252-257. [http://dx.doi.org/10.1016/0002-9378(94)90478-2]

12. Dwivedi P, Puri M, Nigam A, Agarwal K. Fetomaternal outcome in pregnancy with severe thrombocytopenia. Eur Rev Med Pharmacol Sci 2012;16(11):1563-1566.

13. ACOG practice bulletin: Thrombocytopenia in pregnancy. Number 6, September 1999. Int J Gynaecol Obstet 1999;67(2):117-128

14. Subbiah M, Kumar S, Kallol KR, Sharma JB, Singh N. Pregnancy outcome in patients with idiopathic thrombocytopenic purpura. Arch Gynecol Obstet 2014;289(2):269-273. [http://dx.doi.org/10.1007/ s00404-013-2958-x]

15. Ambler KL, Vickars LM, Leger CS, et al. Immune thrombocytopenia in the HAART era. Adv Hematol 2012(2012), Article ID 910954. [http://dx.doi.org/10.1155/2012/910954]

Accepted 14 October 2015. 